\title{
Trends in bilateral mastectomy for cases of unilateral breast cancer in a Brazilian institute over a 10-year period
}

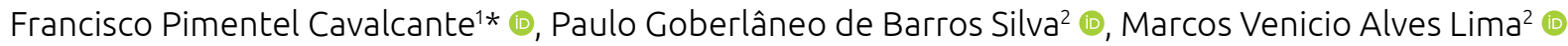

\section{ABSTRACT}

Introduction: There has been a substantial increase worldwide in the number of women with unilateral breast cancer who undergo bilateral mastectomy. Possible contributing factors include the advent of nipple-sparing mastectomy (NSM) and an improvement in breast reconstruction techniques. This study evaluated the trend in bilateral mastectomy at the Ceará Cancer Institute in Brazil. Methods: Patients with unilateral breast cancer who underwent mastectomy and immediate breast reconstruction were evaluated retrospectively between 2009 and 2018. Clinical, pathological and surgical factors were analyzed to determine their possible effects on the type of surgery performed. Results: Of 121 patients, 77 (63.6\%) were submitted to unilateral mastectomy, while 44 (36.4\%) underwent bilateral mastectomy. Most were treated with NSM ( $n=66 ; 54.5 \%)$, with this technique being significantly associated with bilateral mastectomy $(p<0.001)$. Bilateral mastectomy increased significantly over the period $\left(p=0.009 ; r^{2}=\right.$ $0.592)$, but unilateral mastectomy did not $\left(p=0.417 ; r^{2}=0.084\right)$. Age $<45$ years $(p=0.007)$ and negative axilla $(p=0.003)$ were also associated with bilateral mastectomy, while axillary dissection was associated with unilateral mastectomy $(p=0.028)$. Multivariate analysis showed the 2016-2018 period to be an independent factor associated with bilateral mastectomy. Conclusions: These results corroborate the international literature. From 2010 onwards, there was a trend towards an increase in bilateral mastectomy with breast reconstruction. These data may contribute to multidisciplinary debates, facilitating the establishment of guidelines. Further studies are required to improve understanding of this phenomenon in Brazil.

KEYWORDS: prophylactic mastectomy; unilateral breast neoplasms; mammaplasty.

\section{INTRODUCTION}

Breast-conserving surgery is the preferred treatment for early breast cancer. Survival rates after long periods of follow-up are comparable to those achieved with radical mastectomy. ${ }^{1-6}$ Currently, the rates of local recurrence are low irrespective of the extent of the surgery; ${ }^{7}$ nevertheless, many patients will still undergo mastectomy.

Skin-sparing (SSM) and nipple-sparing mastectomy (NSM) facilitate breast reconstruction and, although no prospective controlled studies have been conducted to evaluate the oncologic safety of these techniques, retrospective studies show adequate local control when compared to radical mastectomy. ${ }^{8,9}$

Recently, various countries have registered increased rates of bilateral mastectomy and a reduction in cases of unilateral mastectomy. ${ }^{10}$ Possible explanations include cancer phobia, the possibility of detecting genetic susceptibility to breast cancer, ${ }^{11}$ and of immediate breast reconstruction, particularly with the use of implants, following SSN or NSM, with the potential to achieve better breast symmetry, ${ }^{12}$ and the greater attention given to the subject by the lay press. This trend, however, has yet to be evaluated in Brazil.

The purpose of the present study was to evaluate this trend in the surgical treatment of breast cancer, specifically bilateral mastectomy and its associated clinical factors, in a setting in which immediate breast reconstruction is available, in women with unilateral breast cancer who were to undergo mastectomy in a reference oncology institute in Brazil.

\section{METHODS}

This retrospective, longitudinal study included women with unilateral breast cancer. The internal review board of the Ceará Cancer Institute approved the study protocol under reference

${ }^{1}$ Hospital Geral de Fortaleza - Fortaleza (CE), Brazil.

IInstituto do Câncer do Ceará - Fortaleza (CE), Brazil.

*Corresponding author: fpimentelcavalcante@gmail.com

Conflict of interests: nothing to declare.

Received on: 04/28/2021. Accepted on: 06/28/2021. 
61.473. Medical records were reviewed and, between 2009 and 2018, patients submitted to mastectomy for the treatment of unilateral invasive breast cancer with recommendation for immediate breast reconstruction were selected. Patients with bilateral breast cancer, breast cancer recurrence or metastatic disease on an initial stage were excluded from the study. The factors evaluated were: whether mastectomy was SSM or NSM, unilateral or bilateral, and the year of the procedure. Data on age, tumor size $(\mathrm{T})$, lymph nodes $(\mathrm{N})$ and molecular subtypes were recorded. Hormone receptor (HR)-positive and HER2-negative tumors were considered luminal, while those expressing HER2 (or FISH/SISH-positive) were classified as HER2, and those that were HR-negative and HER2-negative were considered triplenegative (TN). The type of axillary surgery, adjuvant treatment (chemotherapy, hormone therapy and radiotherapy) and the presence of the inherited pathogenic mutations that predispose to cancer were also evaluated. Clinical outcomes were classified as local and/or regional recurrences, distant recurrences or death resulting from breast cancer. Follow-up of at least three months was required to determine any failure or major complications (skin necrosis, infection or hematoma that required reoperation) in breast reconstruction.

Data were expressed as absolute frequencies and percentages. Associations with the type of mastectomy were determined by using Fisher's exact test or Pearson's $\chi^{2}$ test. To determine the factors independently associated with unilateral or bilateral mastectomy, the variables with $\mathrm{p}<0.20$ were selected using a forward stepwise approach to build a multinomial logistic regression model.

Linear regression was performed to establish the rate profile of bilateral and unilateral mastectomies over the evaluation period. The SPSS statistical software package for the social sciences, version 20.0 for Windows, was used. A significance level of $95 \%$ was adopted throughout the analysis.

\section{RESULTS}

The medical records of 341 patients were reviewed and 121 met the inclusion criteria. Between 2009 and 2018,77 patients (63.6\%) underwent unilateral mastectomy, while 44 (36.4\%) underwent bilateral mastectomy. Most were treated with NSM ( $n=66 ; 54.5 \%)$, a method significantly more common among the patients undergoing bilateral mastectomy $(\mathrm{p}<0.001)$ (Table 1).

Bilateral mastectomies were more common in patients $<45$ years of age $(p=0.007)$. Of those undergoing bilateral mastectomy, only two had a pathogenic mutation, BRCA, in both cases. $\mathrm{T} 1(\mathrm{n}=38 ; 36.2 \%)$ and N0 $(\mathrm{n}=33,56.9 \%)$ were the most prevalent tumor stage and node status, respectively. Distant metastases were found in 7 patients (8.0\%). Node status was significantly associated with bilateral mastectomy $(p=0.003)$ (Table 2$)$.

Table 1. Profile of mastectomies performed between 2009 and 2018.

\begin{tabular}{l|c|c|c|c|}
\multirow{2}{*}{ Total } & \multicolumn{5}{|c}{ Mastectomy } \\
\cline { 2 - 5 } & Total & Unilateral & Bilateral & p-value \\
\cline { 2 - 5 } & $121(100 \%)$ & $77(63.6 \%)$ & $44(36.4 \%)$ & - \\
\hline
\end{tabular}

Surgery

\begin{tabular}{|c|c|c|c|c|}
\hline Nipple-sparing mastectomy & $66(54.5 \%)$ & $31(40.3 \%)$ & $35(79.5 \%)^{*}$ & $<0.001$ \\
\hline Skin-sparing mastectomy & $55(45.5 \%)$ & $46(59.7 \%)^{*}$ & $9(20.5 \%)$ & \\
\hline \multicolumn{5}{|l|}{ Year } \\
\hline 2009 & $2(1.7 \%)$ & $2(2.6 \%)$ & $0(0.0 \%)$ & $<0.001$ \\
\hline 2010 & $8(6.6 \%)$ & $8(10.4 \%)$ & $0(0.0 \%)$ & \\
\hline 2011 & $4(3.3 \%)$ & $3(3.9 \%)$ & $1(2.3 \%)$ & \\
\hline 2012 & $2(1.7 \%)$ & $2(2.6 \%)$ & $0(0.0 \%)$ & \\
\hline 2013 & $7(5.8 \%)$ & $6(7.8 \%)$ & $1(2.3 \%)$ & \\
\hline 2014 & $23(19.0 \%)$ & $22(28.6 \%) *$ & $1(2.3 \%)$ & \\
\hline 2015 & $19(15.7 \%)$ & $16(20.8 \%) *$ & $3(6.8 \%)$ & \\
\hline 2016 & $13(10.7 \%)$ & $5(6.5 \%)$ & $8(18.2 \%)^{*}$ & \\
\hline 2017 & $10(8.3 \%)$ & $3(3.9 \%)$ & $7(15.9 \%)$ & \\
\hline 2018 & $33(26.3 \%)$ & $10(13.0 \%)$ & $23(52.3 \%)^{*}$ & \\
\hline \multicolumn{5}{|l|}{ Period } \\
\hline $2009-2015$ & $65(53.7 \%)$ & $59(76.6 \%) *$ & $6(13.6 \%)$ & $<0.001$ \\
\hline $2016-2018$ & $56(46.3 \%)$ & $18(23.4 \%)$ & $38(86.4 \%)^{*}$ & \\
\hline
\end{tabular}

${ }^{*} p<0.05$. Fisher's exact test or Pearson's $\chi^{2}$ test $(n ; \%)$. 
Most tumors were HR-positive $(\mathrm{n}=63,78.8 \%)$ and HERnegative $(\mathrm{n}=70,87.5 \%)$. Only 9 tumors $(11.3 \%)$ were TN. Tumor phenotype was similar in the two groups ( $p>0.05$ ) (Table 2).

Adjuvant radiotherapy was administered to 53 patients (51.0\%) and was not associated with unilateral or bilateral mastectomy $(\mathrm{p}=0.116)$. Ten patients $(11.1 \%)$ developed postoperative complications and three patients (2.5\%) suffered local recurrence, unassociated with the type of mastectomy performed in both cases ( $p=0.717$ and $p=1.000$, respectively) (Table 3 ). Positive sentinel lymph nodes were found in 62 patients (59.0\%), with no difference between the two groups $(p=0.292)$. Thirtytwo patients $(30.5 \%)$ underwent axillary dissection, which was significantly associated with unilateral mastectomy ( $\mathrm{p}=$ 0.028). Most of the patients ( $\mathrm{n}=71 ; 71.7 \%)$ underwent chemotherapy, with no association with the type of mastectomy performed ( $p=0.102)$. Chemotherapy was neoadjuvant in $53 \%$ of cases. Most women received hormone therapy $(\mathrm{n}=74 ; 85.1 \%)$,

Table 2. Effect of age at diagnosis, clinical staging and tumor phenotype on the profile of the mastectomies performed.

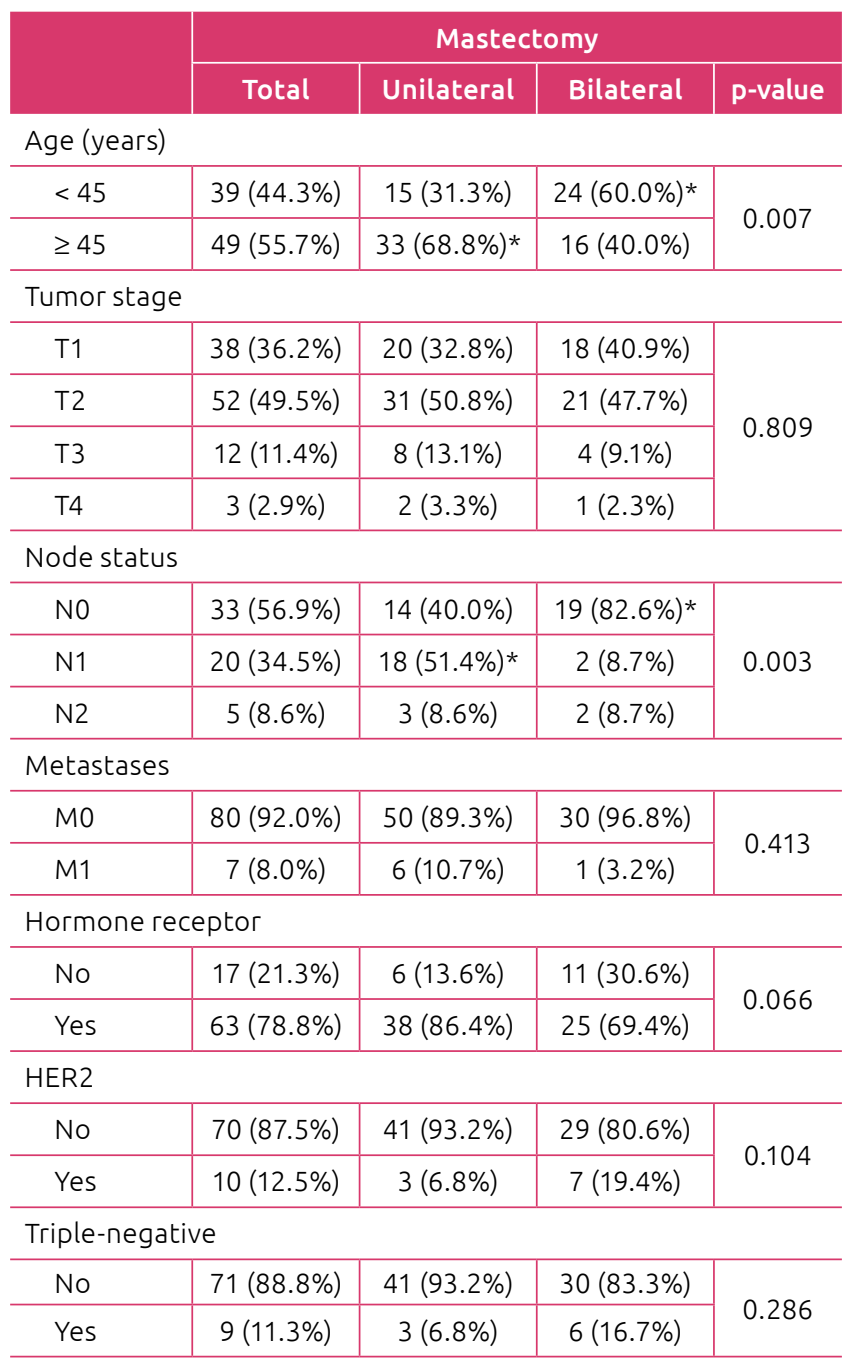

${ }^{*} p<0.05$. Fisher's exact test or Pearson's $\chi^{2}$ test $(n ; \%)$. which was associated with unilateral mastectomy $(\mathrm{p}=0.013)$. Six deaths occurred (7.5\%), unassociated with the type of mastectomy performed $(\mathrm{p}=0.092)$ (Table 3$)$.

Bilateral mastectomy increased significantly $\left(\mathrm{p}=0.009, \mathrm{r}^{2}=\right.$ $0.592)$ over the period. Conversely, unilateral mastectomy did not $\left(\mathrm{p}=0.417, \mathrm{r}^{2}=0.084\right)$ (Figure 1). The number of bilateral mastectomies was significantly higher than unilateral mastectomies from 2016 onwards $(\mathrm{p}<0.001)$ (Table 1). In the multivariate analysis, the 2016-2018 period was independently associated with bilateral mastectomy, with an odds ratio of 11.53 (95\%CI 1.26-105.71) in relation to unilateral mastectomy $(\mathrm{p}=0.031)($ Table 4$)$.

\section{DISCUSSION}

This study found increasing rates of bilateral mastectomy, particularly after 2016. Conversely, unilateral mastectomy did not increase significantly over this period. A study based on the Surveillance,

Table 3. Additional treatment and outcome according to the type of mastectomy performed.

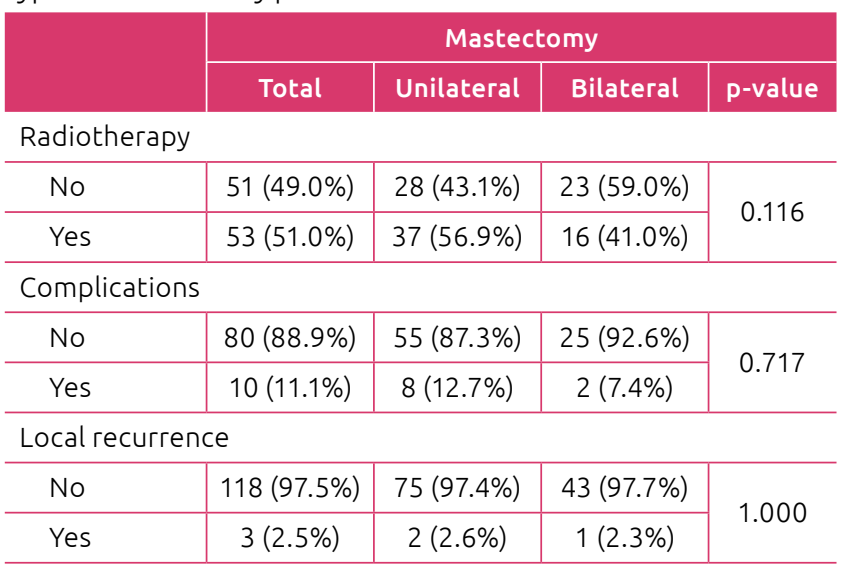

Positive sentinel lymph node

\begin{tabular}{|c|c|c|c|c|}
\hline No & $43(41.0 \%)$ & $28(45.2 \%)$ & 15 (34.9\%) & \multirow{2}{*}{0.292} \\
\hline Yes & $62(59.0 \%)$ & 34 (54.8\%) & $28(65.1 \%)$ & \\
\hline \multicolumn{5}{|c|}{ Axillary dissection } \\
\hline No & $73(69.5 \%)$ & $38(61.3 \%)$ & 35 (81.4\%)* & \multirow{2}{*}{0.028} \\
\hline Yes & $32(30.5 \%)$ & $24(38.7 \%) *$ & $8(18.6 \%)$ & \\
\hline \multicolumn{5}{|c|}{ Chemotherapy } \\
\hline \multirow[t]{2}{*}{ No } & $28(28.3 \%)$ & $17(28.3 \%)$ & $11(28.2 \%)$ & \multirow{3}{*}{0.102} \\
\hline & $32(32.3 \%)$ & $15(25.0 \%)$ & $17(43.6 \%)$ & \\
\hline Adjuvant & 39 (39.4\%) & $28(46.7 \%)$ & $11(28.2 \%)$ & \\
\hline
\end{tabular}

Hormone therapy

\begin{tabular}{c|c|c|c|c}
\hline No & $13(14.9 \%)$ & $4(7.3 \%)$ & $9(28.1 \%) *$ & \multirow{2}{*}{0.013} \\
\cline { 1 - 4 } Yes & $74(85.1 \%)$ & $51(92.7 \%) *$ & $23(71.9 \%)$ & \\
\cline { 1 - 3 } Death & $74(92.5 \%)$ & $47(88.7 \%)$ & $27(100.0 \%)$ & \multirow{2}{*}{0.092} \\
\cline { 1 - 3 } No & $6(7.5 \%)$ & $6(11.3 \%)$ & $0(0.0 \%)$ & \\
\hline Yes &
\end{tabular}

${ }^{*} \mathrm{p}<0.05$. Fisher's exact test or Pearson's $\chi^{2}$ test $(n ; \%)$. 
Epidemiology and End Results (SEER) program showed an increase in contralateral mastectomy in the United States from $1.8 \%$ in 1998 to $4.5 \%$ in $2003 .^{13}$ Simultaneously, conservative treatment remained stable, indicating that the preference for contralateral mastectomy is especially for women undergoing major surgery. ${ }^{14}$

The present rate of bilateral mastectomy was higher compared to earlier studies, ${ }^{13,14}$ particularly in cases of NSM. Having selected patients for whom immediate breast reconstruction was available may have affected our results: preservation of the entire skin envelope of the breast facilitates reconstruction involves more discrete scars, and may affect the decision to perform bilateral surgery. ${ }^{15} \mathrm{~A}$ retrospective study by the American National Cancer Database (NCDB) showed that in women submitted to surgery between 1998 and 2011, contralateral surgery increased 7\% for each percentage point of increase in reconstruction ${ }^{16}$.

More women have opted for bilateral mastectomy despite a paradoxical decline in the rates of contralateral disease in recent years. Following the introduction of systemic treatment, the annual risk of contralateral cancer fell from $0.5 \%$ to around $0.1 \%$ annually. ${ }^{17}$ Overestimation of the risk may have affected the planning of surgeries. Germline mutations such as the BRCA1/2 gene mutations are known to play a role in the appearance of new breast tumors, with bilateral surgery often being recommended in such cases. ${ }^{18}$ Nevertheless, in this study, only two patients were confirmed to have one of the inherited gene mutations..$^{19,20}$ Most of the prophylactic surgeries were probably performed based on family history and on the patients' personal decisions. A survey showed that only $38.1 \%$ of the patients with unilateral breast cancer knew that the contralateral prophylactic surgery had no effect on survival. ${ }^{21}$

Age also affected the results, with $56 \%$ of the women under 50 years of age undergoing bilateral surgery compared to $27 \%$ of the

Table 4. Multinomial logistic regression for predictive factors of bilateral mastectomy.

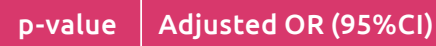

Bilateral mastectomy

\begin{tabular}{l|c|c}
\hline Surgery (NSM) (SSM) & 0.431 & - \\
\hline Year (2016-2018) & 0.031 & $11.53(1.26-105.71)$ \\
\hline Age (<45 years) & 0.322 & - \\
\hline Node (+) & 0.375 & - \\
\hline Hormone Receptor (-) & 0.218 & - \\
\hline HER2 (+) & 0.998 & - \\
\hline Radiotherapy (Yes) & 0.874 & - \\
\hline Axillary dissection (No) & 0.994 & - \\
\hline Chemotherapy (Yes) & 0.938 & - \\
\hline Hormone therapy (No) & 0.655 & - \\
\hline Death (No) & 1.000 & - \\
\hline
\end{tabular}

${ }^{*} \mathrm{P}<0.05$; OR: odds ratio; $95 \% \mathrm{Cl}$ : $95 \%$ confidence interval for the adjusted OR; SSM: skin-sparing mastectomy; NSM: nipple-sparing mastectomy. older patients, and a significant association being found between age $<45$ years and bilateral surgeries. Likewise, data from the California Cancer Registry revealed that bilateral surgery was associated with younger age, with the rates increasing from 3,6\% in 1998 to $33 \%$ in 2011, an increase of almost 10 times within little more than ten years. ${ }^{22}$

Neoadjuvant chemotherapy (NACT), traditionally used in cases of locally advanced cancer, has recently been indicated to facilitate breast conservation also in operable tumors. ${ }^{23}$ Paradoxically, its use in the present study was associated with bilateral mastectomy in $53 \%$ of cases. A recent NCDB-based study reported similar results following the evaluation of almost 60,000 women submitted to NACT between 2010 and 2014. ${ }^{24}$ Despite the increase in full pathological response over the time period, the rates of breast conservation increased slightly from $37.0 \%$ to $40.8 \%(\mathrm{p}=0.22)$ and bilateral mastectomy rates with immediate breast reconstruction increased from $8 \%$ to $13.1 \%$, with a reduction in unilateral mastectomy. In the present study, bilateral surgery increased for patients with aggressive chemosensitive disease (70\% of HER 2 and $67 \%$ of the TN cases), although they would normally be potential candidates for NACT and conservative surgeries. Conversely, in luminal tumors, the bilateral surgery rate was lower: $30 \%$ of the cases. Better understanding is required regarding the reason why many patients who are eligible for breast-conserving surgeries decide that mastectomy is necessary. One of the possibilities is the fear of recurrence of the disease and the false impression that mastectomy is a "safer" treatment. ${ }^{25}$

In the present study, bilateral surgery was more closely associated with early-stage breast cancer. Patients with negative axilla were more likely to undergo bilateral surgery, whereas those who had undergone axillary dissection were more likely to have had a unilateral surgery. In general, the impact of a prophylactic surgery tends to be lower in the advanced stages of the disease, which may have affected these results.

Breast reconstruction failure, the most serious local complication in this procedure, was low in the present analysis, irrespective of laterality. In a cohort of 471 patients from Yale University, $58 \%$ underwent bilateral surgery, with complication rates being similar to those found with unilateral surgery (re-operation: $11.2 \%$ versus $10.8 \%$ ). ${ }^{26}$ Bilateral prophylactic mastectomy was associated with a longer hospitalization period, a factor that was not evaluated in the present study. Most cases of breast reconstruction today are performed with the use of implants, minimizing surgical complications. Women undergoing reconstruction with autologous flaps, ${ }^{27}$ which prolongs surgery and increases associated morbidity, were not included in the present study.

\section{CONCLUSION}

In conclusion, these results corroborate the international literature. From 2010 onwards, there was a trend towards an increase in bilateral mastectomy with breast reconstruction. These data may contribute to multidisciplinary debates, facilitating the 
establishment of guidelines. Nevertheless, further studies are required to increase understanding of this phenomenon and the impact it produces in the country.

\section{AUTHORS' CONTRIBUTION}

F.P.: Conceptualization, data curation, formal analysis, investigation, methodology, project administration, resources, supervision, validation, visualization, writing — original draft, writing review \& editing.

M.V.: Conceptualization, data curation, formal analysis, investigation, methodology, project administration, resources, supervision, validation, visualization, writing — original draft, writing - review \& editing.

P.G.: Data curation, formal analysis, methodology, resources, software, validation, visualization, writing - review \& editing.

\section{REFERENCES}

1. Fisher B, Anderson S, Bryant J, Margolese RG, Deutsch M, Fisher ER, et al. Twenty-year follow-up of a randomized trial comparing total mastectomy, lumpectomy and lumpectomy plus irradiation for the treatment of invasive breast cancer. N Engl J Med. 2002;347(16):1233-41. https://doi.org/10.1056/nejmoa022152

2. Veronesi U, Cascinelli N, Mariani L, Greco M, Saccozzi R, Luini A, etal.Twenty-year follow-up of a randomized studycomparing breast-conserving surgery with radical mastectomy for early breast cancer. N Engl J Med. 2002;347(16):1227-32. https://doi. org/10.1056/nejmoa020989

3. Dongen JA, Voogd AC, Fentiman IS, Legrand C, Sylvester RJ, Tong D, et al. Long-term results of a randomized trial comparing breast-conserving therapy with mastectomy: European Organization for Research and Treatment of Cancer 10801 trial. J Natl Cancer Inst. 2000;92(14):1143-50. https://doi. org/10.1093/jnci/92.14.1143

4. Poggi MM, Danforth DN, Sciuto LC, Smith SL, Steinberg SM, Liewehr DJ, et al. Eighteen-year results in the treatment of early breast carcinoma with mastectomy versus breast conservation therapy: the National Cancer Institute Randomized Trial. Cancer. 2003;98(4):697-702. https://doi.org/10.1002/cncr.11580

5. Blichert-Toft M, Rose C, Andersen JA, Overgaard M, Axelsson CK, Andersen KW, et al. Danish randomized trial comparing breast conservation therapy with mastectomy: six years of lifetable analysis. J Natl Cancer Inst Monogr. 1992;(11):19-25.

6. Arriagada R, Lê MG, Rochard F, Contesso G. Conservative treatment versus mastectomy in early breast cancer: patterns of failure with 15 years of follow-up data. J Clin Oncol. 1996;14(5):1558-64. https://doi.org/10.1200/jco.1996.14.5.1558

7. Fisher B, Dignam J, Bryant J, DeCillis A, Wickerham DL, Wolmark N, et al. Five versus more than five years of tamoxifen therapy for breast cancer patients with negative lymph nodes and estrogen receptor-positive tumors. J Natl Cancer Inst. 1996;88(21):1529-42. https://doi.org/10.1093/jnci/88.21.1529

8. Lanitis S, Tekkis PP, Sgourakis G, Dimopoulos N, Al Mufti RA, Hadjiminas DJ. Comparison of skin-sparing mastectomy versus non-skin-sparing mastectomy for breast cancer: a metaanalysis of observational studies. Ann Surg. 2010;251(4):632-9. https://doi.org/10.1097/sla.0b013e3181d35bf8

9. Galimberti V, Morigi C, Bagnardi V, Corso G, Vicini E, Fontana SK, et al. Oncological outcomes of nipple-sparing mastectomy: a single-center experience of 1989 patients. Ann Surg Oncol. 2018;25(13):3849-57. https://doi.org/10.1245/s10434-018-6759-0
10. Neuburger J, Macneill F, Jeevan R, van der Meulen JH, Cromwell DA. Trends in the use of bilateral mastectomy in England from 2002 to 2011: retrospective analysis of hospital episode statistics. BMJ Open. 2013;3(8):e003179. https://doi. org/10.1136/bmjopen-2013-003179

11. Metcalfe K, Gershman S, Ghadirian P, Lynch HT, Snyder C, Tung $\mathrm{N}$, et al. Contralateral mastectomy and survival after breast cancer in carriers of BRCA1 and BRCA2 mutations: retrospective analysis. BMJ. 2014;348:g226. https://doi.org/10.1136/bmj.g226

12. Albornoz CR, Matros E, Lee CN, Hudis CA, Pusic AL, Elkin E, et al. Bilateral Mastectomy versus breast-conserving surgery for early-stage breast cancer: the role of breast reconstruction. Plast Reconstr Surg. 2015;135(6):1518-26. https://doi. org/10.1097/prs.0000000000001276

13. Tuttle TM, Habermann EB, Grund EH, Morris TJ, Virnig BA. Increasing use of contralateral prophylactic mastectomy for breast cancer patients: a trend toward more aggressive surgical treatment. J Clin Oncol. 2007;25(33):5203-9. https:// doi.org/10.1200/jco.2007.12.3141

14. Habermann EB, Abbott A, Parsons HM, Virnig BA, Al-Refaie WB, Tuttle TM. Are mastectomy rates really increasing in the United States? J Clin Oncol. 2010;28(21):3437-41. https://doi. org/10.1200/jco.2009.27.6774

15. Cavalcante FP, Lima MV. Nipple-sparing mastectomy with periareolar incision and two-stage reconstruction: initial analysis of 31 cases. Breast J. 2018;24(6):940-3. https://doi. org/10.1111/tbj.13114

16. Kummerow KL,DuL, Penson DF, ShyrY,Hooks MA.Nationwide trends in mastectomy for early-stage breast cancer.JAMA Surg. 2015;150(1):9-16. https://doi.org/10.1001/jamasurg.2014.2895

17. Nichols HB, González AB, Lacey Jr. JV, Rosenberg PS, Anderson WF. Declining incidence of contralateral breast cancer in the United States from 1975 to 2006. J Clin Oncol. 2011;29(12):15649. https://doi.org/10.1200/jco.2010.32.7395

18. Valachis A, Nearchou AD, Lind P. Surgical management of breast cancer in BRCA-mutation carriers: a systematic review and meta-analysis. Breast Cancer Res Treat. 2014;144(3):44355. https://doi.org/10.1007/s10549-014-2890-1

19. Reiner AS, Sisti J, John EM, Lynch CF, Brooks JD, Mellemkjær L, et al. Breast cancer family history and contralateral breast cancer riskin young women: an update from the Women's Environmental Cancer and Radiation Epidemiology Study. J Clin Oncol. 2018;36(15):1513-20. https://doi.org/10.1200/jco.2017.77.3424 
20. Wright FC, Hong NJ, Quan ML, Beyfuss K, Temple S, Covelli A, et al. Indications for contralateral prophylactic mastectomy: a consensus statement using modified delphi methodology. Ann Surg. 2018;267(2):271-9. https://doi.org/10.1097/sla.0000000000002309

21. Jagsi R, Hawley ST, Griffith KA, Janz NK, Kurian AW, Ward KC, et al. Contralateral prophylactic mastectomy decisions in a populationbased sample of patients with early-stage breast cancer. JAMA Surg. 2017;152(3):274-82. https://dx.doi.org/10.1001\%2Fjamasurg.2016.4749

22. Kurian AW, Lichtensztajn DY, Keegan TH, Nelson DO, Clarke CA, Gomez SL. Use of and mortality after bilateral mastectomy compared with other surgical treatments for breast cancer in California, 1998-2011.JAMA. 2014;312(9):902-14. https://dx.doi. org/10.1001\%2Fjama.2014.10707

23. Wolmark N, WangJ, Mamounas E, BryantJ, Fisher B. Preoperative chemotherapy in patients with operable breast cancer: nine-year results from National Surgical Adjuvant Breast and Bowel Project B-18. J Natl Cancer Inst Monogr. 2001;(30):96-102. https://doi. org/10.1093/oxfordjournals.jncimonographs.a003469
24. Pollom EL, Qian Y, Chin AL, Dirbas FM, Asch SM, Kurian AW, et al. Rising rates of bilateral mastectomy with reconstruction following neoadjuvant chemotherapy. Int $\mathrm{J}$ Cancer. 2018;143(12):3262-72. https://doi.org/10.1002/ijc.31747

25. Huang J, Chagpar A. Complications in patients with unilateral breast cancer who undergo contralateral prophylactic mastectomy versus unilateral mastectomy. Surgery. 2018;164(6):1347-50. https://doi.org/10.1016/j. surg.2018.05.044

26. Marks LB, Gupta GP, Muss HB, Ollila DW. Mastectomy may be an inferior oncologic approach compared to breast preservation. Int J Radiat Oncol Biol Phys. 2019;103(1):78-80. https://doi.org/10.1016/j.ijrobp.2018.07.2021

27. Massenburg BB, Sanati-Mehrizy P, Ingargiola MJ, Rosa JH, Taub PJ. Flap failure and wound complications in autologous breast reconstruction: a national perspective. Aesthetic Plast Surg. 2015;39(6):902-9. https://doi.org/10.1007/s00266015-0575-8 